\title{
A Cross-Sectional Study to assess the Oral Mucosal Conditions of Institutionalized Elderly People in India
}

INTRODUCTION: Institutionalized health care is expensive in most of the developing countries such as India. Due to which people residing in old care homes were having higher rate of oral disease.

OBJECTIVES: To assess oral mucosal condition of institutionalized elderly people living in India.

MATERIALS AND METHOD: A cross sectional survey was conducted among the 8old care homes in India and clinical examination was done to check any mucosal changes of oral cavity among the studied subjects. After the data collection descriptive statistics was done by using SPSS 22.0 version.

RESULTS: Majority of the people were having oral mucosal conditions i.e. $31.75 \%$ and $26.35 \%$ of the total study participants had OSMF (Oral Submucous Fibrosis) and Denture Stomatitis respectively.

CONCLUSION: The present study concludes that oral mucosal condition is relatively poor in institutionalized elderly living

KEYWORDS: Dental health, Oral care, Geriatric, Oral condition.

\section{INTRODUCTION}

Man, from time immemorial is trying to prolong the life span with the help of various medical innovations and intervention. With the help of it, the average life span of an individual has increased and quality of life has improved. Therefore, the group of people above the age of 60 is on rise. ${ }^{1}$

In common with other developing nation, Indian population is experiencing a demographic revolution too. ${ }^{2}$ Currently, at the national level $8.0 \%$ of total population is in the age group of 60 years and above. Moreover it is expected to be doubled in coming ten years. The scenario is changing and surveys on geriatric people have highlighted poor oral health. ${ }^{2-4}$

It is recognized that in developing countries like India institutionalized health care is expensive. Thus individual residing in geriatric homes have higher rate of oral disease. ${ }^{5}$ In order to promote the oral health of elderly, we need to know the oral health status and treatment needs. Hence, the present study was conducted with the aim to assess oral mucosal condition of institutionalized elderly living in old care homes of India.

\section{METHODOLOGY}

A cross sectional survey was conducted to assess the oral mucosal condition of institutionalized elderly people living in old care homes of India. Ethical clearance was obtained from the institutional review board of the college. Permission for the data collection was obtained from the concerned authorities of the selected geriatric homes and informed consent was obtained before the examination from each participant. A list of 11 old care homes was obtained from the District headquarters and social organizations. Among them only o8 gave the permission to carry out the survey. The study participants were selected based on the following criteria.

\section{Inclusion criteria:}

1. Subjects consenting to participate in the study.

2. Subjects who are present on the day of study.

\section{Exclusion criteria:}

1. Physically challenged and mentally compromised elderly people, and those with cognitive impairment.

2. Elderly people with terminal illness.

The clinical examination was carried out by a trained and calibrated examiner. The intra-examiner variability was checked by carrying out repeated examination on $10 \%$ randomly selected participants and intra-examiner kappa coefficient values i.e. 0.78 were calculated.

The study Performa consisted of two parts. The first part was a structured questionnaire to record the following information on age, sex and habit related to tobacco and alcohol. The second part was to record the oral mucosal condition of the study subject using WHO Oral Health Assessment Performa (2013). The collected was then subjected to analysis by SPSS 22.0(Statistical Package for Social Sciences, Chicago, 
IL, USA) version for analysis and descriptive statistics of data was done.

\section{RESULTS}

The study population consisted of 264 institutionalized elderly aged 55 years and above with their mean age of 60 years. Out of 264 study subjects, $67.23 \%$ of them were males and $32.77 \%$ of them were females (Table 1).

It was seen that $10 \%$ of the study subjects had habit of consuming tobacco and $17 \%$ of alcohol. $37 \%$ of males had habit of consuming smokeless tobacco previously. In terms of oral mucosal conditions, $31.75 \%$ and $26.35 \%$ of the total study participants had OSMF (Oral Submucous Fibrosis) and Denture Stomatitis respectively(Table 2 ). $29.08 \%$ and $17.23 \%$ of the male study subjects had OSMF and Denture Stomatitis respectively. Among the female study subjects, OSMF and Denture Stomatitis were $13.03 \%$ and $20.33 \%$ respectively (Figure 1).

The most prevalent locations of oral mucosal conditions among study subjects were buccal mucosa and alveolar ridge and it was found to be present among $21.94 \%$ and $11.4 \%$ of the male study subjects respectively. $3.03 \%$ and $22.43 \%$ of the female study subjects had oral mucosal condition in buccal mucosa and alveolar ridge respectively. Totally $13.8 \%$ of the study subjects had the oral mucosal condition in the buccal mucosa and $16.15 \%$ of the study subjects had oral mucosal condition in the alveolar ridge (Figure 2).

\section{DISCUSSION}

Ageing is a universal phenomenon associated with deteriorating health status. It is said that nobody grows old merely by living a certain number of years. With the passage of time certain changes take place in an organism leading to morbidities, disabilities and even death. ${ }^{7}$

In the present study, few of the study subjects had habit of consuming tobacco and alcohol. The reason was prohibition of tobacco and alcohol consumption in geriatric homes. The present study results show that, the percentage of OSMF among the study subjects was $31.75 \%$. The prevalence may probably be due to the use of tobacco among the study subjects. Definite fibrous band on palpation was used as a main diagnostic criterion for OSMF. However, studies conducted by Tang et al. ${ }^{6}$ and Yang et al. ${ }^{7}$, OSMF was present in $5.49 \%$ and $23.2 \%$ of the study subject respectively. The analysis of study results show that, the percentage of denture stomatitis among the study subjects was $26.35 \%$. This is similar to the study conducted by Mujica $\mathrm{V}$ et al. ${ }^{8}$, where denture stomatitis was present in $18 \%$ of the study subjects. The possible reason could be poor oral hygiene among the elderly. Studies conducted by Espinoza I. et al. ${ }^{9}$ and Sahebjamee $\mathrm{M}$ et al. $^{10}$ show that, denture stomatitis was seen among $22.3 \%$ and $35.5 \%$ of study subject respectively. Different sites in oral cavity show inclination toward different disease. It is known that certain lesions are more common in certain parts of the oral cavity. The present study results show that, $13.8 \%$ of the study subjects had oral mucosal condition in the buccal mucosa. These may be because of the use of smokeless tobacco products which are commonly kept in the buccal vestibule for a longer period of time which may lead to fibrosis of buccal mucosa. ${ }^{11}$ The study conducted by Patil S et al." shows that, the most commonly affected site was hard palate which was $23.1 \%$, where as $12.3 \%$ of the study subjects has oral mucosal lesion located on the buccal mucosa.

Most common disease present among dentures wearing patients is denture stomatitis. It is chronic inflammatory disease of the soft tissue. ${ }^{12}$ The present study result shows that, $16.15 \%$ of study subjects had Denture stomatitis on the alveolar ridge. The possible reason may be due to misfit dentures, continuous wear of dentures, presence of Candida and other microorganism, faulty design of dentures which distribute uneven load on supporting structures and causes resorption of the bone. Whereas, the study conducted by Tatjana $\mathrm{P}$ et al. ${ }^{12}$ showed, $46.7 \%$ and $26.7 \%$ of the study subjects had denture stomatitis in upper and lower jaw respectively.

\section{CONCLUSION}

There is a need to encourage public health care administrators and decision-makers to design effective and affordable strategies and programmes for better oral health and quality of life of the institutionalized elderly, which are integrated into general health programmes. Dental care is vital to maintain natural teeth and enhance the quality of life for elderly people. The overall objective of dental therapy is to preserve dentition by preventing the progression of dental diseases. It should be integrated into overall health management of all geriatric patients and its maintenance is crucial to stability and functional health of the tissues. Preserving good oral health starts early in life by developing healthy lifestyles, practicing 
appropriate self-care, and regularly using oral health services when available.

\section{REFERENCES}

1. Bansal V, Sogi GM, Veeresha KL. Assessment of oral health status and treatment needs of elders associated with elders' homes of Ambala division, Haryana, India. Indian J Dent Res 2010; 21: 244-7.

2. Shenoy RP, Hengde V. Dental prosthetic status and prosthetic needs of the institutionalized elderly living in geriatric homes in Manglore: A pilot study. ISRN Dent 2011; 2011: 1-3.

3. Government of India. India Census 2011. Available from: http:// www.censusindia.gov.in/2011- common/ census data online.html

4. Mary AV, Ebenezar R, Chaly PE, Ingle N, Reddy VC. Oral health status and treatment needs of geriatric population of old age homes of Chennai city. India. J Oral Health Res. 2010; 2(1):82-6.

5. Purna Singh A, Lokeshkumar K, Reddy CM Pavankumar. Psychiatric Morbidity in geriatric population in old age homes and community: A comparative study. Indian J Psychol Med 2012; 34(1): 39-43.

6. Choudhary M et al. Morbidity pattern and treatment seeking behaviour of geriatric population in Jamnagar city. Res Med Den Sci. 2013; 1:12-16.

7. Tang J-G, Jian X-F, Gao M-L, Ling T-Y, Zhang K-H: An epidemiological survey of oral submucous fibrosis in Xiangtan City, Hunan Province, China. Cotninunity Dent Oral Fpidctniol 1997; 25: 177-80.
8. Yang YH, Lee HY, Tung S, Shieh TY. Epidemiological survey of oral submucous fibrosis and leukoplakia in aborigines of Taiwan. J Oral Pathol Med 2000; 30: 2139.

9. Mujica V, Rivera H, Carrero M. Prevalence of oral soft tissue lesions in an elderly venezuelan population. Med Oral Patol Oral Cir Bucal. 2008; 13(5):270-4.

10. Espinoza I, Rojas R, ArandaW, Gamonal J. Prevalence of oral mucosal lesions in elderly people in Santiago, Chile. J Oral Pathol Med 2003; 32: 571-5.

11. Sahebjamee M, BasirShabestari S, Asadi G, Neishabouri K. Predisposing Factors associated with Denture Induced Stomatitis in Complete Denture Wearers. Shiraz Univ Dent J 2011;11: 35-9.

12. Patil Santosh P, Doni B, Maheshwari S. Prevalence and Distribution of Oral Mucosal Lesions in a Geriatric Indian Population. Canad Geriatrics J 2015; 18(1): 11-4 13. Puškar T, Michal P, Dubravka M, Slobodan P, Danimir J, Tijana L, Larisa B. Factors influencing the occurrence of denture stomatitis in complete Dentures wearers. Health MED 2012; 6(8): 2780-5.
Source of support: Nil, Conflict of interest: None declared
Cite this article as:

A Cross-Sectional Study to assess the Oral Mucosal Conditions of Institutionalized Elderly People in India. Int Healthcare Res J 2018;2(3):.

doi: 10.26440/IHRJ/02_03/

\section{AUTHOR AFFILIATIONS:}

Senior Lecturer, BRS Dental College, Sultanpur, Panchkula, India

2. Consultant Periodontist, Clove Dental, Mohali, Punjab, India

Corresponding Author:

Dr. Ravneet Randhawa

Senior Lecturer

BRS Dental College

Sultanpur, Panchkula, India
For article enquiry/author contact details, e-mail at: manuscriptenquiry.ihri@gmail.com 


\section{LEGENDS}

\begin{tabular}{|c|c|c|}
\hline \multicolumn{2}{|c|}{ Characteristic } & \multirow{2}{*}{$\begin{array}{c}\text { Frequency } \\
\begin{array}{c}(\%) \\
67.23 \%\end{array}\end{array}$} \\
\hline Gender & Male & \\
\hline & Female & $32.77 \%$ \\
\hline \multirow[t]{2}{*}{ Age groups } & 40-6o years & $47 \%$ \\
\hline & 61 years and above & $53 \%$ \\
\hline \multirow[t]{2}{*}{ Habits } & Tobacco consumption & $10 \%$ \\
\hline & Alcohol consumption & $17 \%$ \\
\hline
\end{tabular}

Table 1. Demographic Data of Study Subjects

\begin{tabular}{|c|c|}
\hline Procedures & $\begin{array}{c}\text { Frequency } \\
(\%)\end{array}$ \\
\hline OSMF & $31.75 \%$ \\
\hline Denture stomatitis & $26.35 \%$ \\
\hline No lesions & $41.93 \%$ \\
\hline
\end{tabular}

Table 2. Frequency of oral mucosal conditions

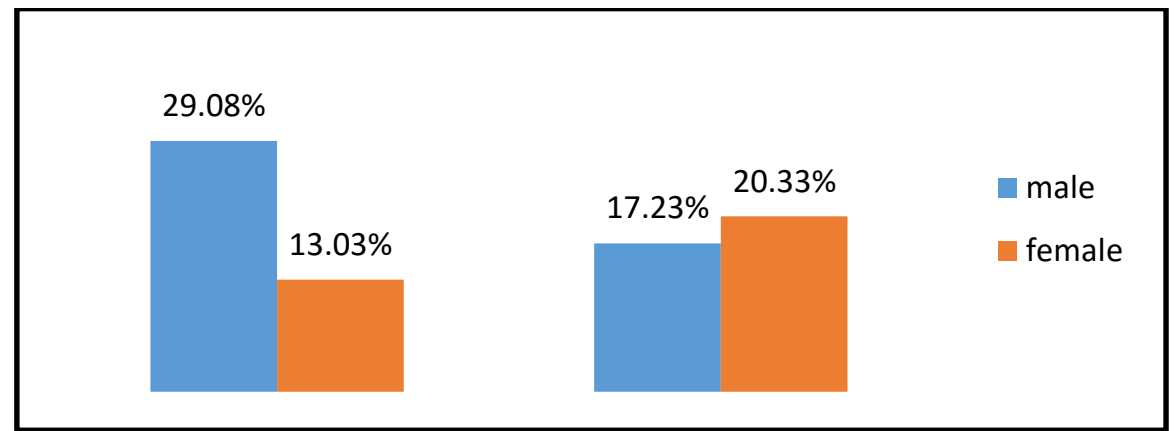

Figure 1. Frequency of oral mucosal conditions

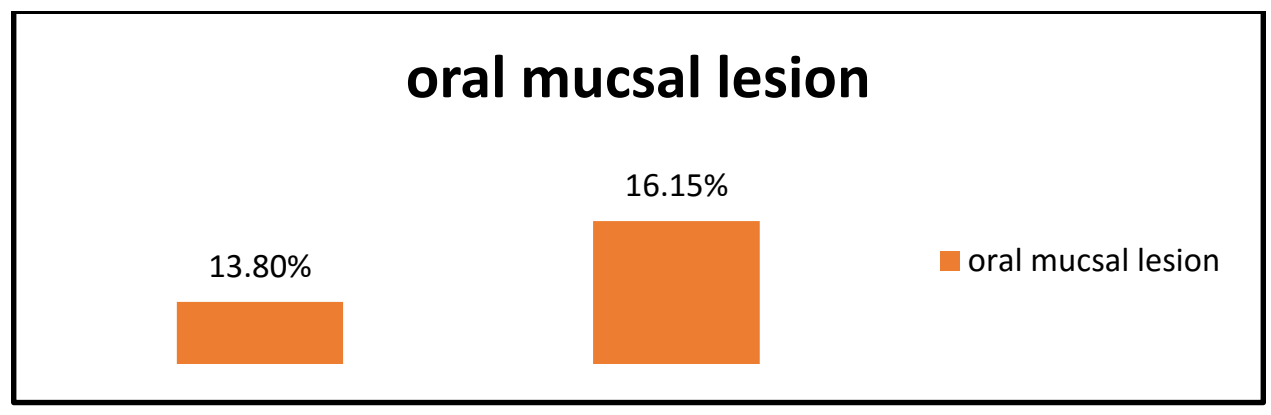

Figure 2. Oral mucosal condition according to distribution of sites 